\title{
Changes to letters in Thorax
}

\section{J R Hurst, J A Wedzicha}

\section{Updated guidelines for authors of letters to Thorax}

$\mathrm{H}$ ere at Thorax we believe that letters are the life blood of a journal. Correspondence in response to published articles provides comment and alternative interpretations of data that promote debate, may be unexpected, and add value to the original work. Readers may also take the opportunity to present complementary research findings in such a letter. Moreover, we also publish research letters in Thorax and these are a useful method to present original and important data, or interesting observations that are too limited in scope to require a complete paper. All our letters are cited in PubMed and linked to the original paper.

We wish to encourage you to submit more letters, to join the debate about the work that we publish, and thus to contribute to the vibrancy of our wonderful specialty. To facilitate this we have updated the author guidelines for letters in Thorax. The changes are also an attempt to make our letters page more timely, more up to date and more succinct, which will enable us to publish more of your correspondence. We have previously trialled a feature where "rapid responses" to a published article were posted online. However, we felt that all correspondence about published articles should be submitted for consideration of publication in the full print journal and thus we discontinued the rapid responses feature.

\section{CORRESPONDENCE ABOUT PUBLISHED PAPERS}

For responses to published articles your letter must reach us by the end of the following calendar month (for example, by the end of July for letters referring to articles in the June print issue) and be a maximum length of 400 words, with one figure or table and no more than five references. However, Thorax has an online repository facility so additional information including methodology, data and tables could be placed in the online supplement. You can also get a head start on debating our published papers by viewing accepted work using our Online First facility in which papers are published online in full as soon as they have been accepted for publication. All letters are submitted through our online submission Bench Press system and we always invite the corresponding author of a paper to comment on letters in response to their work. However, as we receive more letters than we can publish, we reject a proportion of letters written in response to published papers. In this case, we always endeavour to supply the authors of a letter with the response received from the original authors.

\section{RESEARCH LETTERS}

For original research letters the maximum length will be 500 words, again with no more than one figure or table and five references. As for correspondence, authors may also make use of the online supplement. All original letters are first seen by one of us, and some of these may be rejected without further review if we feel they do not reach a standard for publication or are not of sufficient interest to the readership of the journal. We send out the remainder of original research letters for further peer review, usually to two reviewers. These letters will then be discussed by the Editors at the regular editorial committee meetings in the same way that we discuss all potentially acceptable papers. However, as with original papers, we also have to reject a significant proportion of the research letters submitted.

Letters pages in the journal are important and help us directly to involve you, our readers. Please keep debates alive in respiratory medicine by writing to Thorax with your comments about the work we have published. This will surely benefit our specialty and stimulate further research.

Thorax 2007;62:474

doi: $10.1136 /$ thx.2007.082685

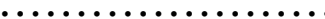

Authors' affiliations

J R Hurst Letter Editor, Thorax Editorial Office J A Wedzicha Editor-in-Chief, Thorax Editorial Office

Correspondence to: Dr J R Hurst, Thorax Editoria Office, BMJ Publishing Group, London WC1H 9JR, UK

\section{Corrections}

Figure 9 of the article by Sarah R Anderson et al in the February issue of Thorax (Tuberculosis in London: a decade and a half of no decline in tuberculosis epidemiology and control. Thorax 2007;62:162-7) was incorrectly labelled. A corrected version of the figure is available at: http:// thorax.bmj.com/cgi/content/full/thx.2006.058313/DC1

Also, the title has been amended and the online version is different to the printed version (revised title: Tuberculosis in London: a decade and a half of no decline).

\section{doi: 10.1136/thx.2006.58313corr}

Appendix 3 of the supplement Pandemic flu: clinical management of patients with an influenzalike illness during an influenza pandemic (Thorax 2007;62(Suppl 1)i1-46) was incorrectly labelled in one part. To the question "Does the patient have pneumonia?" the Yes and No labels on the following arrows were swapped. A corrected version of the figure is available at: http://thorax.bmi.com/cgi/content/full/62/suppl_1/1/DCl

doi: 10.1136/thx.2007.073080corr 1 